\title{
Transcription factor AP-I in esophageal squamous cell carcinoma: Alterations in activity and expression during Human Papillomavirus infection
}

\author{
Showket Hussain ${ }^{1}$, Alok C Bharti ${ }^{1}$, Irfana Salam², Mohammad Akbar Bhat ${ }^{3}$, \\ Mohammad Muzaffar Mir ${ }^{2}$, Suresh Hedau${ }^{1}$, Mushtaq A Siddiqi ${ }^{4}$, \\ Seemi Farhat Basir ${ }^{5}$ and Bhudev C Das*1,6
}

\begin{abstract}
Address: ${ }^{1}$ Division of Molecular Oncology, Institute of Cytology \& Preventive Oncology (ICMR), I-7, Sector-39, Noida, India, ${ }^{2}$ Department of Clinical Biochemistry, Sher-I-Kashmir Institute of Medical Sciences, Soura, Srinagar, Jammu and Kashmir, India, ${ }^{3}$ Department of Cardiovascular and Thoracic Surgery, Sher-I-Kashmir Institute of Medical Sciences, Soura, Srinagar, Jammu and Kashmir, India, ${ }^{4}$ Department of Immunology and Molecular Medicine Sher-I-Kashmir Institute of Medical Sciences, Soura, Srinagar, Jammu and Kashmir, India, ${ }^{5}$ Department of Biosciences, Jamia Millia Islamai; New Delhi, India and ${ }^{6}$ Dr. B.R. Ambedkar Research Centre for Biomedical Research (ACBR), University of Delhi (North Campus), Delhi, India

Email: Showket Hussain - shussain1712@yahoo.co.in; Alok C Bharti - bhartiac@icmr.org.in; Irfana Salam - irfanasalam@gmail.com; Mohammad Akbar Bhat - drmakbarbhat@yahoo.co.uk; Mohammad Muzaffar Mir - mirmuzaffar11@gmail.com; Suresh Hedau - suresh_hedau@hotmail.com; Mushtaq A Siddiqi - siddiqimushtaq@yahoo.co.in; Seemi Farhat Basir - seemifb@gmail.com; Bhudev C Das* - dasbc@acbr.du.ac.in

* Corresponding author
\end{abstract}

Published: 16 September 2009

BMC Cancer 2009, 9:329 doi:10.1186/1471-2407-9-329
Received: 6 May 2009

Accepted: 16 September 2009

This article is available from: http://www.biomedcentral.com/I47I-2407/9/329

(c) 2009 Hussain et al; licensee BioMed Central Ltd.

This is an Open Access article distributed under the terms of the Creative Commons Attribution License (http://creativecommons.org/licenses/by/2.0), which permits unrestricted use, distribution, and reproduction in any medium, provided the original work is properly cited.

\begin{abstract}
Background: Esophageal squamous cell carcinoma (ESCC) is a leading cause of cancer-related deaths in Jammu and Kashmir (J\&K) region of India. A substantial proportion of esophageal carcinoma is associated with infection of high-risk HPV type 16 and HPVI8, the oncogenic expression of which is controlled by host cell transcription factor Activator Protein-I (AP-I). We, therefore, have investigated the role of DNA binding and expression pattern of AP-I in esophageal cancer with or without HPV infection.
\end{abstract}

Methods: Seventy five histopathologically-confirmed esophageal cancer and an equal number of corresponding adjacent normal tissue biopsies from Kashmir were analyzed for HPV infection, DNA binding activity and expression of AP-I family of proteins by PCR, gel shift assay and immunoblotting respectively.

Results: A high DNA binding activity and elevated expression of AP-I proteins were observed in esophageal cancer, which differed between HPV positive (19\%) and HPV negative (8I\%) carcinomas. While JunB, c-Fos and Fra-I were the major contributors to AP-I binding activity in HPV negative cases, Fra-I was completely absent in HPVI6 positive cancers. Comparison of AP-I family proteins demonstrated high expression of JunD and c-Fos in HPV positive tumors, but interestingly, Fra-I expression was extremely low or nil in these tumor tissues.

Conclusion: Differential AP-I binding activity and expression of its specific proteins between HPV - positive and HPV - negative cases indicate that AP-I may play an important role during HPVinduced esophageal carcinogenesis. 


\section{Background}

Esophageal squamous cell carcinoma (ESCC) is one of the most common cancers in the world with extremely poor prognosis due to late presentation and rapid progression. It is eighth among the most common cancers worldwide and fifth most common cancer in developing countries [1]. ESCC shows a great variation in geographic distributions and the incidence rates are remarkably higher in distinct areas such as China, Singapore, Iran, France, South Africa, Puerto Rico, Chile, Brazil and northern and eastern Himalayan region. The wide geographical variation in the incidence reflects strong influence of environmental factors [2]. This cancer is also a major health problem in India; particularly in Kashmir valley and is associated with characteristic food and drinking habits such as drinking of hot salted tea which contains carcinogenic compounds like nitrosamines [3]. Besides salted tea, tobacco smoking (Hukka; local name Jajjer) is also very common in this area and is a potential risk factor for increased incidence of esophageal cancer $[2,4,5]$. Though recent reports have documented alterations of some oncogenes and tumor suppressor genes, the exact molecular and genetic basis of esophageal carcinogenesis still remains poorly understood [6].

Several studies have demonstrated infection of human papillomaviruses (HPVs) in esophageal cancer world over [7]. Though prevalence of this virus varies between 10 $70 \%$ from one geographical region to other, the infection of high risk HPV (HR-HPV) types mainly HPV type 16 and HPV18 is found to be the most common in almost all parts of the world [8]. Our earlier study has also demonstrated that a significant proportion of esophageal cancer cases from Kashmir region are infected with HR-HPV type 16 [9]. This and other studies [7-9] indicate an oncogenic role of HR-HPV types in esophageal carcinogenesis. Since the virus does not have its own transcriptional machinery, the expression of its two transforming oncogenes, E6 and E7, depends primarily on availability of host cell transcription factors, particularly the Activator Protein-1 (AP1) $[10,11]$. It has been demonstrated that a point mutation in the AP-1 consensus sequence within the binding site of upstream regulatory region (URR) of HPV16/18 leads to complete abolition of E6 and E7 gene expression [12]. Recent study also indicates that HPV infection may result in reciprocal alteration in AP-1 activity and its composition that could affect downstream gene expression and signaling leading to tumorigenesis of the infected cells [13] and better prognosis [14]. However, currently there is no study that defines the role of AP-1 in HPV induced esophageal carcinogenesis.

Considering the important role of AP-1 in a variety of epithelial cancers in general and those infected with HPV in particular, the present study has been carried out to inves- tigate the possible relationship between HPV infection and expression profile of AP- 1 family proteins in association with other etiological factors in the development of ESCC in Kashmir valley.

\section{Methods \\ Patients and Specimens}

A total of 150 tissue specimens comprising of 75 tumor tissues and 75 corresponding adjacent normal tissues as a control of ESCC, from 25 cases with no dysphagia and 50 cases of either grade I, II, and III dysphagia as classified earlier [15], were collected for analysis in the present study [Table 1]. None of these patients received any preoperative radiation or chemotherapy. All samples were surgically resected and were collected at the Department of Cardio Vascular and Thoracic Surgery of Sher-I-Kashmir Institute of Medical Sciences, Soura, Srinagar, Kashmir (India). Tissue samples were divided into two parts; one part was sent to histopathological diagnosis and other half was stored in $-70^{\circ} \mathrm{C}$ for molecular investigations. Histopathological grades and clinical staging were evaluated according to standard criteria [16] by two pathologists independently with 17 cases graded as well-differentiated squamous cell carcinoma (WDSSC), 45 as moderatelydifferentiated squamous cell carcinoma (MDSCC) and 13 as poorly-differentiated squamous cell carcinoma (PDSCC) whereas 46 patients were scored as stage I \& II and 29 as stage III \& IV. Only histopathologically confirmed cases were included for molecular analysis. Written informed consent was obtained from all the subjects included in the study and was carried out in accordance with the principles of the Helsinki Declaration. The study was approved by the Ethics Committee of the Hospital and the institute.

\section{DNA extraction and PCR detection of HPV}

High molecular-weight genomic DNA was isolated from tumor and normal adjacent tissue specimens by standard proteinase $\mathrm{K}$ digestion and a phenol-chloroform extraction procedure routinely followed in our laboratory [17]. PCR for detection of HPV16 and HPV18 DNA were carried out as described previously [18], using type-specific primers [HPV16 (1), 5-AAG GCC AAC TAA ATG TCA C-3; HPV16 (2), 5-CTG CTT TTA TAC TAA CCG G-3; HPV18 (1), 5-ACC TTA ATG AAA AAC CAC GA-3; HPV18 (2), 5CGT CGT TTA GAG TCG TTC CTG-3]. Initially, all DNA samples were tested for the presence of HPV by using a pair of consensus primers located within the conserved L1 open reading frame (ORF) of the HPV genome (MY 11, 5GCM CAG GGW CAT AAY AAT GC-3; MY 09, 5-CGT CCM ARR GGA WAC TGA TC-3; where $\mathrm{M}=\mathrm{A} / \mathrm{C}, \mathrm{W}=\mathrm{A} / \mathrm{T}, \mathrm{Y}=$ $\mathrm{C} / \mathrm{T}, \mathrm{R}=\mathrm{A} / \mathrm{G})$. PCR was performed in a $25 \mu \mathrm{l}$ reaction mix containing 100 ng DNA, $10 \mathrm{mM}$ Tris- $\mathrm{HCl}(\mathrm{pH}$ 8.4), 50 $\mathrm{mM} \mathrm{KCl}, 1.5 \mathrm{mM} \mathrm{MgCl}, 125 \mu \mathrm{M}$ of each dNTP (dATP, dCTP, dGTP and dTTP), 5 pmol of each oligonucleotide 
Table I: Clinico-pathological and demographic characteristics and HPV status of Esophageal Squamous Cell Carcinoma cases investigated from Kashmir region.

\begin{tabular}{|c|c|c|}
\hline Characteristics & Subgroup & Patients $n=75$ (\%age) \\
\hline \multicolumn{3}{|l|}{ Gender } \\
\hline Male & & $43(57)$ \\
\hline Female & & $32(43)$ \\
\hline \multicolumn{3}{|l|}{ Age } \\
\hline $40-60$ years & Mean age (57.5) & $47(63)$ \\
\hline$>60$ years & & $28(37)$ \\
\hline \multicolumn{3}{|l|}{ Smoking Status } \\
\hline Smoker & & $5 I(68)$ \\
\hline Non-smoker & & $24(32)$ \\
\hline \multicolumn{3}{|l|}{ Dysphagia } \\
\hline & Grade I, II, III & $50(67)$ \\
\hline & No Dysphagia & $25(33)$ \\
\hline \multicolumn{3}{|l|}{ Location of tumor } \\
\hline & Upper & $10(13)$ \\
\hline & Middle & $60(80)$ \\
\hline & Lower & $5(7)$ \\
\hline \multicolumn{3}{|l|}{ Clinical Stage } \\
\hline & Stage I \& II & $46(61)$ \\
\hline & Stage III \& IV & 29(39) \\
\hline \multicolumn{3}{|l|}{ Histological Grade } \\
\hline & WDSCC & $17(23)$ \\
\hline & MDSCC & $45(60)$ \\
\hline & PDSCC & $13(17)$ \\
\hline \multicolumn{3}{|c|}{ Consumption of hot salted tea/day } \\
\hline \multirow[t]{3}{*}{ With sodium bicarbonate } & I-3 cups & $20(27)$ \\
\hline & 3-6 cups & $38(51)$ \\
\hline & $>6$ cups & $10(13)$ \\
\hline
\end{tabular}


Table I: Clinico-pathological and demographic characteristics and HPV status of Esophageal Squamous Cell Carcinoma cases investigated from Kashmir region. (Continued)

\begin{tabular}{lcc}
\hline Without sodium bicarbonate & & $7(9)$ \\
\hline HPV status & HPV LI Positive & $14(19 \%)$ \\
\hline Tumor Tissues & HPVI6 & 14 (I00\%) Nil \\
\cline { 2 - 3 } & Other HPVs & Nil \\
\hline Normal Adjacent Tissues & HPV LI Positive & \\
\hline
\end{tabular}

primer and 0.5 U Taq DNA polymerase (Perkin-Elmer Biosystems, Foster City, CA, USA). The temperature profile used for amplification constituted an initial denaturation at $95^{\circ} \mathrm{C}$ for $5 \mathrm{~min}$ followed by 35 cycles with denaturation at $95^{\circ} \mathrm{C}$ for $30 \mathrm{sec}$, annealing at $55^{\circ} \mathrm{C}$ for 30 sec and extension at $72^{\circ} \mathrm{C}$ for $1 \mathrm{~min}$, which was extended for $4 \mathrm{~min}$ in the final cycle. The oligonucleotide primers were synthesized in an automated Applied Biosystems DNA synthesizer (Model 381A; Applied Bio-systems, Foster City, CA, USA) using the phosphoramidite method and purified in high performance liquid chromatography (HPLC).

\section{Preparation of protein extract}

Protein extracts from all ESCC biopsies (cancer and normal adjacent control) were prepared by the method of Dignam [19] with minor modification described earlier [14] Briefly, frozen tissues were minced and resuspended in ice-cold buffer A [20 mM HEPES (pH 7.6), 20\% (v/v) Glycerol, $10 \mathrm{mM} \mathrm{NaCl}, 1.5 \mathrm{mM} \mathrm{MgCl} 2,0.2 \mathrm{mM}$ EDTA, 1 $\mathrm{mM}$ DTT, $1 \mathrm{mM}$ PMSF, $2 \mu \mathrm{g} / \mathrm{ml}$ Leupeptin and $10 \mu \mathrm{g} / \mathrm{ml}$ Aprotinin]. The lysates were microfuged at 4,000 rpm for $10 \mathrm{~min}$ at $4^{\circ} \mathrm{C}$ after incubating them for 15 min on ice. The supernatant was transferred in a new tube and designated as cytoplasmic extracts. The pellet containing isolated nuclei was resuspended in the 2 times pellet amount of extraction buffer B [20 mM HEPES (pH 7.6), 25\% (v/v) Glycerol, $500 \mathrm{mM} \mathrm{NaCl}, 1.5 \mathrm{mM} \mathrm{MgCl} 2,0.2 \mathrm{mM}$ EDTA, $1 \mathrm{mM}$ DTT, $1 \mathrm{mM}$ PMSF, $2 \mu \mathrm{g} / \mathrm{ml}$ Leupeptin and $10 \mu \mathrm{g} / \mathrm{ml}$ Aprotinin]. The extraction mixture was microfuged after 1 hr at $14,000 \mathrm{rpm}$ at $4{ }^{\circ} \mathrm{C}$ for $25 \mathrm{~min}$. The resulting supernatant was designated as nuclear extract. The concentration of protein in the extracts was determined by standard Bradford method (Bio-Rad Laboratories, Inc.CA) and the extracts were stored at $-70^{\circ} \mathrm{C}$ freezer until use.

\section{Electrophoretic mobility shift assay}

For electrophoretic mobility shift assay (EMSA), the following oligonucleotides were used: AP-1 consensus sequence 5 - CGCTTGATGACTCAGCCGGAA-3 (consensus binding sites are underlined and italicized), and Oct-
1 consensus oligonucleotide 5-TGTCGAATGCAAATCACTAGAA-3. The oligonucleotide probes were synthesized in an Applied Biosystems DNA synthesizer using phosphoramidite chemistry. The above oligonucleotides were annealed and labelled with $\left[\gamma^{32} \mathrm{P}\right]$ ATP $(3,000 \mathrm{Ci} /$ mmol; Jonaki, Hyderabad, India) by T4 polynucleotide kinase and gel purified in a $15 \%$ polyacrylamide gel [20]. The binding reaction was performed in a $25 \mu \mathrm{l}$ reaction volume containing 50\% glycerol, $60 \mathrm{mM}$ HEPES $(\mathrm{pH}$ 7.9), $20 \mathrm{mM}$ Tris-HCl (pH 7.9), $300 \mathrm{mM} \mathrm{KCl,} 5 \mathrm{mM}$ EDTA, $5 \mathrm{mM}$ DTT, $100 \mu \mathrm{g}$ of BSA per milliliter, $2.5 \mu \mathrm{g}$ of poly (dI-dC) and $10 \mu \mathrm{g}$ of nuclear extract. After $5 \mathrm{~min}$, $10,000 \mathrm{cpm}$ of the $\left[\gamma^{32} \mathrm{P}\right]$ ATP 5 -end labelled doublestranded oligonucleotide probe was added and the incubation was continued for additional $25 \mathrm{~min}$ at room temperature. For monitoring AP-1 composition in supershift assays, $2 \mu \mathrm{g}$ of polyclonal antibodies (Abs) directed against all the Jun and Fos family members (Santa Cruz Biotechnology Inc., Santa Cruz, CA) were added and the reaction mixture was further incubated for $1 \mathrm{hr}$ at $4^{\circ} \mathrm{C}$. The following Abs were used: anti-c)un (epitope corresponding to amino-terminal domain of mouse c-Jun p39); anti-JunB (epitope corresponding to carboxy terminal domain of mouse JunB); anti-JunD (epitope corresponding to carboxy terminus of mouse JunD); anti-cFos (epitope corresponding to a highly conserved domain of cFos p62 of human origin); anti-FosB (epitope corresponding to amino acids within the central domain of the FosB protein of mouse origin); anti-Fra-1 (epitope corresponding to amino terminus of Fra- 1 of rat origin) and anti-Fra-2 (epitope corresponding to carboxy terminus of Fra-2 of human origin). The DNA-protein complexes were resolved on $4.5 \%$ non-denaturing polyacrylamide gel, PAGE (cross-linking ratio, 29:1), dried and exposed overnight to Phosphoimager (Fuji Film-Fla-5100) or Kodak XOmat Films (Kodak India Ltd., India). The quantitative densitometric analysis was performed on shifted and super-shifted bands as a percent loss of band intensity indicating AP-1 binding in reaction having no antibody using Alpha Ease FC version 4.1.0 (Alpha Innotech Corporation. IL) 


\section{Western blotting}

Protein extracts (50 $\mu \mathrm{g}$ of protein per lane) were resolved in $10 \%$ polyacrylamide gel, electrotransferred to Immobilon-P membranes (Millipore Corporation, Bedford, $\mathrm{MA}$ ), and probed with polyclonal rabbit antibodies of the corresponding family members of AP-1 as indicated in previous section. The incubation was carried out overnight in PBS supplemented with 5\% skim milk powder, 0.05\% Tween 20 (Sigma-Aldrich, CHEMIE GmbH, Germany), and different dilutions of respective antibodies. The bands were visualized with anti-rabbit immunoglobulin G (IgG) antibody conjugated with horseradish peroxidase using the Amersham $\mathrm{ECL}^{\mathrm{Tm}}$ western blotting detection reagent kit (GE Healthcare). The blots were stripped and re-probed for $\beta$-actin levels to confirm equal loading and normalization. The expression levels of different AP-1 members were evaluated by densitometry using Alpha Digidoc version 4.1.0 (Alpha Innotech Corporation, IL) on a scale of $0-255$ and the averaged pixel values were re-grouped for analysis on an arbitrary scale as strong => 50\%; medium $=10-50 \%$; weak $=1-10 \%$ and nil/not detectable $<1 \%$ as described earlier [21].

\section{Statistical Analysis}

Statistical analysis on the data was performed using EpiInfo version 6.0 software (Center of Disease Control and Prevention, Atlanta, USA) and SigmaPlot version 10.0 (Systat Software, Point Richmond, CA). The association between HPV infection and expression profile with disease severity and clinico-pathological parameters was determined using the Fischer's Exact Test or Chi Square and Students t-test in order to compare the fold change of AP-1 binding between HPV positive and HPV negative ESCC cases. These tests were considered statistically significant when $\mathrm{p} \leq 0.05$.

\section{Results}

A total of consecutive 75 surgically resected and histopathologically confirmed esophageal tumors along with corresponding normal adjacent tissues were analyzed to study the activity and expression of AP-1 in relation to HPV infection. Various clinico-epidemiological characteristics of esophageal squamous cell carcinoma cases from Kashmir valley and the status of their HPV infection is presented in Table 1 . The cases investigated had slightly higher male representation (male to female ratio 1:0.74) with an average age of 57.5 years. With respect to tobacco consumption, $68 \%$ of the patients had smoking history and $67 \%$ of cases demonstrated various grades of dysphagia. Clinically, 39\% cases had late presentation in either stage III or stage IV. Histopathologically, $60 \%$ of cases belonged to moderately differentiated squamous cell carcinoma Table 2. Patient stratification with respect to consumption of hot-salted tea containing sodium bicarbonate which is considered as a potent car- cinogen in local Kashmiri population revealed consumption of three or more cups of salted tea per day by more than two third of the patient group.

\section{Prevalence of Human Papillomavirus infection in ESCC}

Since HPV is considered as one of the important risk factor in esophageal carcinogenesis, tissue samples were screened by PCR for HPV infection using HPV L1consensus primers (Figure 1A), which revealed presence of HPV infection in 14 out of 75 tumor biopsies (19\%) whereas, no HPV could be detected in any of the normal adjacent tissues. Subsequent PCR- based HPV typing using type-specific primers revealed that all 14 HPV L1 positive esophageal tumors were infected with HPV type 16 (Figure 1B). None of the HPV-infected esophageal tumors showed co-infection with other high- risk/low-risk HPV types.

To determine cofactors that may increase the risk of HPV infection in esophageal cancer, association of HPV infection with various clinico-pathological and demographic characteristics was examined [Table 2]. Majority of HPV infection was confined to patients with smoking history $(\mathrm{p}=0.03)$ or having any grade (I, II or III) of dysphagia. A higher occurrence of HPV infection was also detected in advanced stage of cancer, both clinically (stage III and stage IV; $\mathrm{p}<0.03$ ) as well as histologically (WDSCC and PDSCC; $\mathrm{p}<0.02$ ). Most interestingly, more than $50 \%$ of HPV infection was confined to patients who were in poorly-differentiated state of the disease. Infection of HPV did not show any association with sex, age, or location of the tumor.

\section{Constitutive activation and DNA binding activity of AP-I in ESCC in the absence or presence of HPV infection}

To investigate the role of AP-1 in epithelial carcinogenesis, we analyzed the status of AP-1 DNA binding activity by gel shift assay in esophageal tumors and compared it with that of normal adjacent tissues. As shown in Figure 2A, the presence of constitutively active AP-1 DNA binding activity was detected in most of the esophageal tumors whereas, it was undetectable or very low in all corresponding normal adjacent tissues. Densitometric analysis of the shifted AP-1 band revealed variability in the degree of binding/activation in different cases ranging from 3 to 8 fold increase with respect to normal tissues. The specificity of AP-1 binding activity was confirmed by re-testing the samples for Oct-1 which is ubiquitously active in all cells and was used as an internal control by performing cold competition assay with 100-fold molar excess of homologous AP-1 and a heterologous Oct-1 cold probe (Figure 2B and $2 \mathrm{C}$ ). In order to examine if HPV infection has any effect on AP-1 binding activity in esophageal cancer, as depicted in representative photograph in Figure 3A, we observed a differential activation of AP-1 in ESCC; an ele- 
Table 2: Association of Human Papillomavirus infection with clinicopathological, and other characteristics of ESCC cases

\begin{tabular}{|c|c|c|c|}
\hline Characteristics $(n=75)$ & \%age & HPV+Ve $(n=14)(\%)$ & p-value \\
\hline Sex & & & 0.22 \\
\hline Male $(n=43)$ & 57 & $6(14)$ & \\
\hline Female $(n=32)$ & 43 & $8(25)$ & \\
\hline Age & & & 0.89 \\
\hline $40-60$ years $(n=47)$ & 63 & $9(19)$ & \\
\hline$>60$ years $(n=28)$ & 37 & $5(18)$ & \\
\hline Smoking Status & & & 0.03 \\
\hline Smoker $(n=5 I)$ & 68 & $13(25)$ & \\
\hline Non-smoker $(n=24)$ & 32 & I(4) & \\
\hline Dysphagia & & & 0.03 \\
\hline Grade I, II \& III (n = 50) & 67 & $13(26)$ & \\
\hline No Dysphagia $(n=25)$ & 33 & $\mathrm{I}(4)$ & \\
\hline Location of tumor & & & 0.37 \\
\hline Upper $(n=10)$ & 13 & $\mathrm{I}(10)$ & \\
\hline Middle $(n=60)$ & 80 & $13(22)$ & \\
\hline Lower (5) & 7 & - & \\
\hline Clinical Stage & & & 0.03 \\
\hline Stage I \& II $(n=46)$ & 61 & $5(11)$ & \\
\hline Stage III \& IV $(n=29)$ & 39 & $9(31)$ & \\
\hline Histological Grade & & & 0.020 \\
\hline $\operatorname{WDSCC}(n=17)$ & 23 & $2(12)$ & \\
\hline $\operatorname{MDSCC}(n=45)$ & 60 & $6(13)$ & \\
\hline $\operatorname{PDSCC}(n=13)$ & 17 & $6(46)$ & \\
\hline
\end{tabular}

vated AP-1 DNA-binding activity was significantly higher in HPV-positive tumors as compared to that in HPV-negative tumor tissues. These observations were reconfirmed by densitometric evaluation of gel shifted bands that showed significantly higher $(\mathrm{p}<0.05)$ AP-1 binding activity in HPV-positive tumors than that of HPV-negative tumors (Figure 3B).
Composition of functional AP-I complex in HPV-negative and HPV-positive esophageal squamous cell carcinoma

Since functional AP-1 complex is constituted either by homo or hetrodimerization between different members of Jun and Fos family of proteins, we analyzed the composition of AP-1 complex in esophageal tumor tissues both in the presence and absence of HPV infection in a gel 


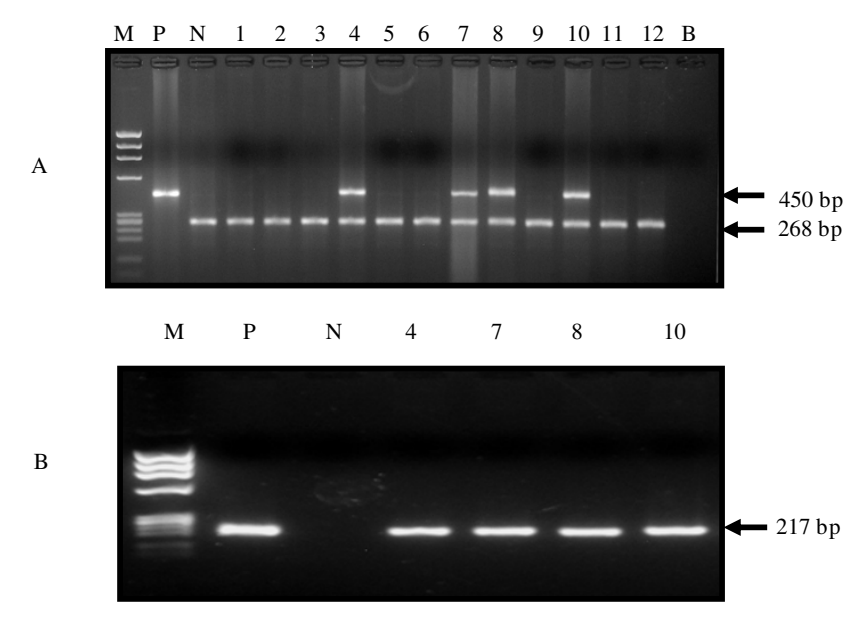

Figure I

(A\&B): Detection of HPV infection by PCR in ESCC cases from Kashmir region. Panel A, Representative ethidium bromide-stained $2 \%$ agarose gel showing presence of HPV infection in esophageal cancer as indicated by appearance of $L I$ consensus primer-generated amplimer of 450 bp along with amplification of 268 bp fragment of $\beta$-globin gene that was used as PCR internal control. Panel B, shows typespecific amplification of HR-HPV type 16 (2I7 bp) in HPV LI positive samples of ESCC. $P=$ positive control (HPVI6DNA), $N=$ negative control (Placental DNA), $B=$ Blank, Lanes I to I 2 are DNA samples from esophageal tumor biopsies, $M=\phi X \mid 74$ Haelll-digested molecular weight marker.

supershift assays by adding specific antibodies to all 7 members of AP-1 e.g. cJun, JunB, JunD, cFos, FosB, Fra-1 and Fra-2 (Figure 4A \&4B). The supershift analysis revealed a preferential hetrodimerization between cFos and JunB instead of its canonical dimerization partner cJun which did not participate in AP-1 complex formation although it showed up-regulated expression in western blotting both in HPV positive as well as HPV negative tumors. In majority of HPV negative tumors more than $85 \%(53 / 61)$ of the supershifts had a JunB participation. Among the Fos family of proteins; mainly cFos was found to be the major contributor but Fra- 1 also showed a minor participation as revealed in band supershift assays. No other Jun or Fos family members showed up in supershift assay (Figure 4B). On the other hand, HPV16-infected (n $=14$ ) tumors also showed major participation of JunB and cFos but the most interesting observation was an exclusive participation of JunD in more than $70 \%$ of cases (10/14). In contrast, Fra-1 was completely absent in functional AP1 activity (Figure 4A). In both HPV-positive and HPV-negative tumors cFos was the major partner contributing more than $90 \%$ participation in the DNA binding activity.

\section{Expression of AP-I family proteins in esophageal squamous cell carcinoma in presence or absence of HPV infection}

Western blotting experiments were performed to analyze the pattern and level of expression of all AP-1 family proteins (cJun, JunB, JunD, cFos, FosB, Fra-1 \& Fra-2) in ESCC cases. Most of the AP-1 family members showed differential expression pattern in esophageal carcinoma tissues compared to their adjacent normal counterparts. While a very low or negligible expression of cJun, JunB, JunD, cFos, FosB, Fra- 1 and Fra- 2 was observed in normal adjacent tissues, the majority of them showed significantly elevated expressions in tumor tissues (Table 3 and Figure 5). In view of the impact of HPV infection on the binding activity and composition of functional AP-1 complex, we examined the expression pattern in HPV-positive and HPV-negative tumors. As shown in Figure 5 and Table 4, we observed a higher level of expression of JunD and cFos in HPV infected cases. Though the expression pattern of other members was higher, there was no significant change in expression pattern of these proteins with respect to HPV infection. Interestingly, unlike in other cancers, Fra-1 expression was diminished or completely lost in tumor tissues infected with HPV16 while HPV-negative tumors showed a very high expression of Fra-1 and also participates in DNA binding as revealed by supershift assay. The higher expression pattern of JunB, JunD, cFos are in concordance with gel shift assays that showed the participation of these proteins in AP-1 complex formation.

\section{Discussion}

Although AP-1 has been demonstrated to play a crucial role in HPV - induced carcinogenesis and oncogenic HRHPVs have been detected in a sizable number of ESCC, there is no study that describes the role of AP-1 in ESCCs. In the present study, we demonstrate for the first time, constitutive activation of AP-1 in ESCCs and change in binding partners that form active AP-1complex in ESCCs. ESCC with HPV infections constituted a significant proportion $(19 \% ; 14 / 75)$ and interestingly all these cases harbored the most prevalent high-risk HPV type 16 . Constitutive activation of AP-1 leading to its high binding activity was observed in most of the esophageal tumors, irrespective of their clinical stage and histo - pathological grade; whereas normal adjacent tissues showed low or no AP-1 activation. Aberrant AP- 1 activity is one of the most frequent mechanisms of tumor promotion in epithelial tissues irrespective of the tumor site and is mediated through activation of its upstream kinases such as ERK, JNK and p38 [22]. Similar to our observation, constitutively active AP-1 has also been observed in other epithelial cell malignancies [21,23-25]. But the mechanism(s) by which AP-1 or its upstream regulatory kinases get activated in ESCC is not known. Apart form physiological reg- 
$\mathbf{A}$

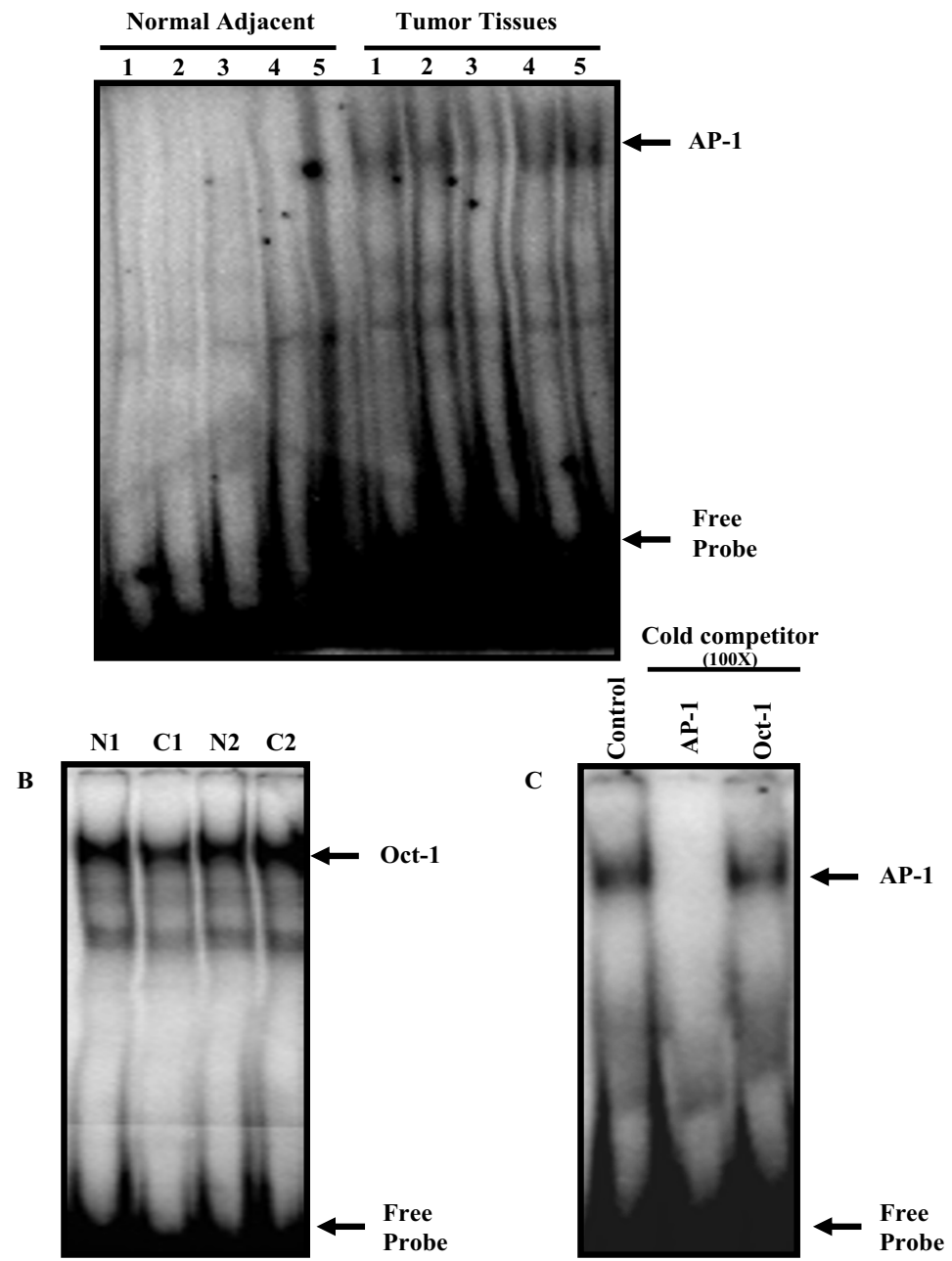

\section{Figure 2}

(A-C): Bandshift assays showing constitutive activation and DNA binding specificity of AP-I in esophageal cancer. (A) nuclear proteins (I0 $\mathrm{gg}$ ) extracted from esophageal tumors (I-5) and their adjacent normal tissues were incubated with $\gamma^{32}$ P-labeled double stranded AP-I binding probe and run on 4.5\% non-denaturing PAGE. (B) uniform binding of Oct-I in normal adjacent tissues and cancer. (C), binding specificity of AP-I in esophageal cancer biopsies was evidenced by adding I00x molar excess of unlabeled homologous competitor, AP-I oligo in competition with heterologous probe Oct-I as indicated in methods. Arrows indicate the position of specific retarded bands.

ulators like growth factors, cytokines or hormones, AP-1 activity is also induced by bacterial and viral infections as well as many carcinogens [26]. Recent study showed that HPV which is found in almost all cervical cancer, can also promote AP-1 activation to a significant level [13,21]. Apart from HPV, other infections such as H. pylori, prevalence of which is notably high in Kashmir region, are also known to induce AP-1 activation [27]. Another factor that could significantly contribute to constitutive activation of AP-1 is consumption of sodium-bicarbonate-brewed hot salted tea which is very widely consumed by majority of people in snow-capped Kashmir Valley [28]. This salted tea it is rich in carcinogenic N-nitroso compounds [3] that primarily act through AP-1 [11]. Interestingly, majority of
ESCC cases investigated in the present study showed AP-1 activation had a high intake of salted tea.

Functional AP-1 complex is constituted either by homoor hetero-dimerization between different members of Jun and Fos family of proteins [25]. Our results demonstrate a preferential participation of JunB and c-Fos in active AP1 complex formation in almost all tumors irrespective of $\mathrm{HPV}$ infection. Interestingly, HPV positive tumors demonstrated an additional participation of JunD in AP-1 DNA binding complex. Also, Fra-1 which showed minor participation in HPV negative tumors was completely absent in HPV positive cases. Apart from formation of heterodimer between Jun and Fos proteins, homodimeriza- 
A

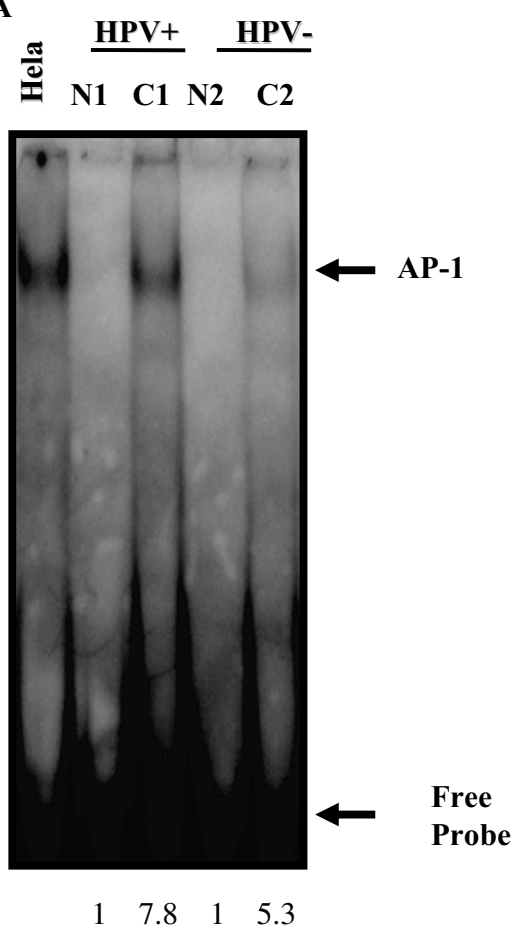

B

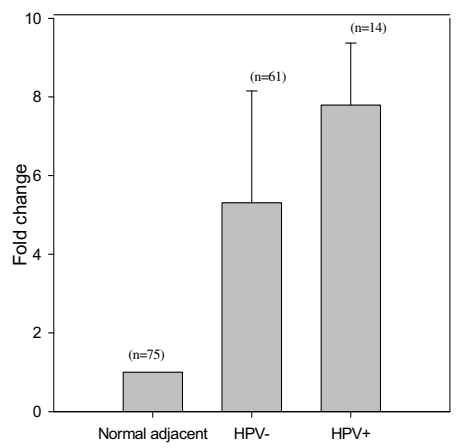

Figure 3

(A\&B): Gel shift analysis showing levels of active AP-I DNA binding complexes present in HPV-positive and HPV-negative esophageal cancer biopsies. (A) $\gamma^{32} \mathrm{P}$-labelled double stranded AP-I oligonucleotides were co-incubated with $10 \mu \mathrm{g}$ of nuclear protein extracts from HPVI 6 positive $(\mathrm{Cl})$, HPV negative $(\mathrm{C} 2)$ esophageal tumor biopsies and corresponding normal adjacent tissues (NI, N2), analyzed on a 4.5\% PAGE. The intensities of the bands were quantified as indicated in methods. Nuclear extracts of HeLa cells, which constitutively express active AP-I, was used as positive control. (B) Mean fold change in AP-I binding activity in HPV negative and HPV positive esophageal cancer with respect to normal adjacent control tissues. Error bars indicate standard deviation, $\mathrm{p}$-value 0.02 as compared to HPV negative tumor tissue. Arrows indicate the position of specific retarded bands.

tion of Jun proteins is also known to form active AP-1 complex but complete absence of cJun in supershift assays indicate that cJun do not participate in functional AP-1 complex formation and hence no jun homodimer formation takes place in ESCC. It is interesting to note here that though c-Jun showed elevated expression in western blotting (see Figure 5), it does not participate in DNA binding activity. It is quite possible that even if a protein is overexpressed, it may not always participate in DNA binding activity and trans-activation possibly due to mutation within the binding sites or otherwise. It can also be speculated that in addition to posttranslational modifications of c-Jun, a simple competition with JunB [29] and JunD to bind with cFos, may also account for the exclusion of cJun from AP-1 complex in esophageal cancer. It is interesting to note that presence of active JunB/cFos dimers may provide a favorable niche for establishment of HPV infection and viral propagation as two AP-1 binding sites are present in URR of HPV18 that essentially require JunB containing hetrodimers for HPV transcription [12]. These observations, therefore, indicate presence of suitable cooperativity between the virus and the host for expression of viral oncogenes.

Most of the ESCC tissues irrespective of their clinical and histopathological grade showed a high expression of AP-1 family of proteins in tumor tissues as compared to their normal counterparts. Upregulated AP-1 activity is frequently associated with overexpression of its family members $[30,31]$. Since majority of AP-1 members are part of immediate early response genes and express differentially in non-neoplastic and neoplastic tissues as well as contribute both in early events of tumorigenesis and tumor progression [30,31], elevated AP-1 expression and activity appears to be generic carcinogenesis-associated event. Though it is well established that AP-1 regulates the expression of HPV oncogenes [10], recent observations indicate that HPV reciprocally modulate AP-1 expression and its activity [13]. We stratified expression levels of AP1 which revealed a differentially higher expression of 
A HPV16+

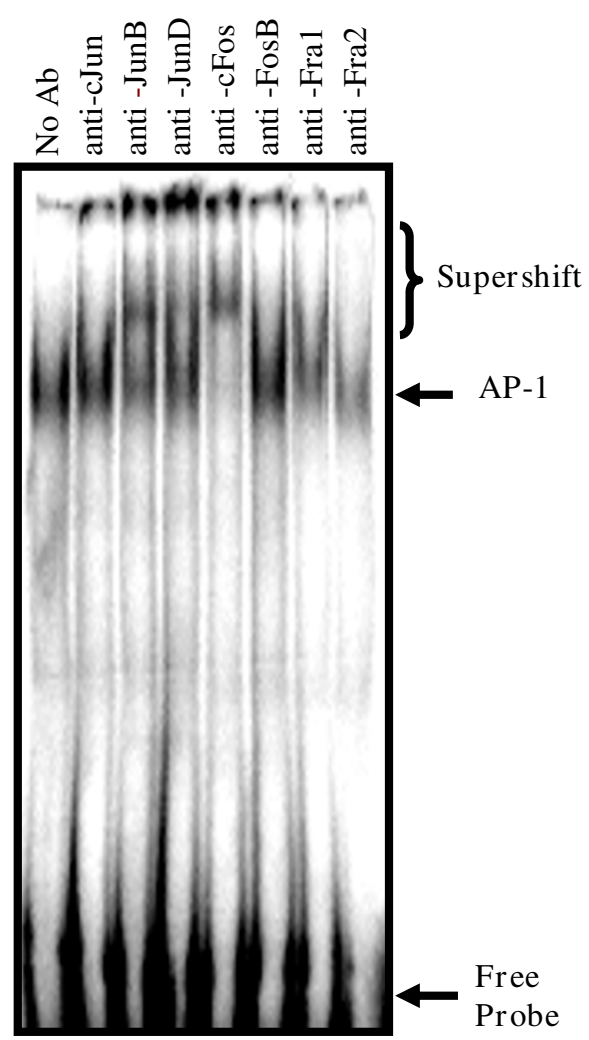

$\begin{array}{lllllll}0 & 0 & 435583 & 0 & 1537 \% & \%\end{array}$
B HPV-

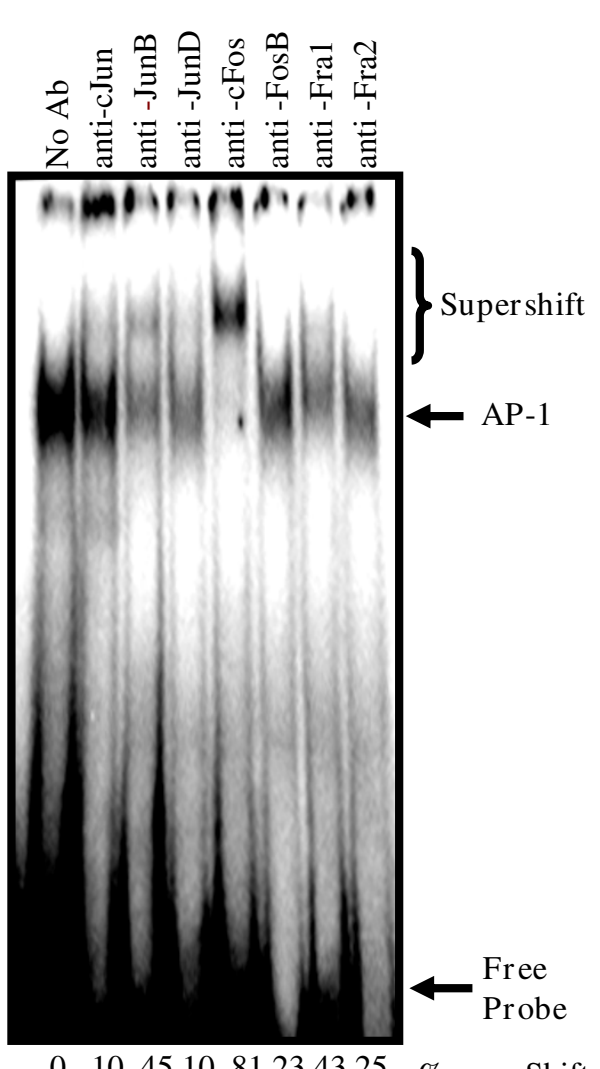

$\begin{array}{llllll}0 & 10 & 4510 & 81234325 \quad \% \text { superShift }\end{array}$

\section{Figure 4}

(A\&B): Band supershift assay showing composition of AP-I complexes in HPV positive and HPV negative esophageal cancer. $10 \mu \mathrm{g}$ of nuclear protein extracts from HPVI6-positive (A) or HPV-negative (B) ESCC biopsies were coincubated with $\gamma^{32}$ P-labeled double stranded AP-I probe. Oligonucleotides and specific antibodies ( $2 \mu \mathrm{g}$ each) to all AP-I family proteins as indicated and analyzed on a 4.5\% PAGE. The intensities of the shifted and super-shited bands were quantified. Supershift was calculated as a percent loss of band intensity indicating AP-I binding in reaction having no antibody.

JunD and cFos proteins in HPV-positive tumors, whereas Fra-1 levels were characteristically low or nil in them. Fra1 was, however, highly expressed in HPV- negative tumors. Over-expression of Fra-1 and cFos have been demonstrated in esophageal cancers in some sporadic studies $[32,33]$. On the contrary, an in vitro study demonstrated increase of cFos in HPV16-transformed cell lines is associated with decreased expression of its negative regulator Fra-1 as well as their reduced contribution in active DNA-binding activity [13]. In an ingenious experiment, overexpression of cFos in HPV 18 positive non-tumorigenic HeLa - Fibroblast hybrid 444 cells having low or no cFos but a very high amount of Fra-1 expression resulted in tumorigenic cells which showed complete loss of Fra-1 but a high expression of cFos [34]. These observations perfectly match with in vivo situations in HPV-infected esophageal tumors, where Fra-1 expression was diminished or completely absent. These observations, therefore, indicate a potential antagonistic effect of HPV infection on Fra-1. Fra-1 have been proposed to have tumor suppressor function as it is located in chromosome 11q13 region which is known to harbor tumor suppressor genes [35] and its over-expression have recently been shown to inhibit cell proliferation, induce apoptosis and reduce tumorigenesity [36]. Moreover, change in AP-1 composition resulting in elimination of Fra-1 has been found to be associated with enhanced tumorigenesity [13,34]. Thus, lack of Fra-1 appears to contributing to more aggressiveness of the disease, as majority of these patients were infected with HPV and in poorly-differentiated state. This is in sharp contrast to our recent observation in oral cancer, where presence of HPV but lack of Fra-1 expression 
Table 3: Expression profile of AP-I proteins in immunoblotting and densitometric analysis of their level of expression in normal adjacent controls and tumor tissues of ESCC.

\begin{tabular}{|c|c|c|c|c|c|c|c|c|c|}
\hline \multirow[t]{2}{*}{ AP-I Family Member Protein } & \multicolumn{4}{|c|}{$\begin{array}{l}\text { Normal } \\
(n=75)\end{array}$} & \multicolumn{4}{|c|}{$\begin{array}{l}\text { Cancer } \\
(n=75)\end{array}$} & \multirow[t]{2}{*}{ p-value } \\
\hline & Nil & Weak & Medium & Strong & Nil & Weak & Medium & Strong & \\
\hline cJun & 10 & 23 & 42 & - & - & 5 & 24 & 46 & 0.001 \\
\hline JunB & 49 & 16 & 8 & 2 & 2 & 9 & 30 & 34 & 0.001 \\
\hline JunD & 53 & 20 & 2 & - & - & 7 & 21 & 47 & 0.001 \\
\hline cFos & 69 & 6 & - & - & - & - & 13 & 62 & 0.001 \\
\hline FosB & 4 & 8 & 36 & 27 & 2 & 14 & 29 & 30 & 0.52 \\
\hline Fra-I & 35 & 12 & 19 & 9 & 11 & 17 & 10 & 37 & 0.003 \\
\hline Fra-2 & 5 & 5 & 28 & 37 & II & 16 & 18 & 30 & 0.002 \\
\hline
\end{tabular}

Arbitrary level of expression in Immunoblotting: strong =>50\%; medium $=10-50 \%$; Weak $=1-10 \%$; and Nil/undetectable $=<1 \%$. Statistical calculation was done by grouping nil \& weak, medium \& strong together. Yates corrected chi-square/Fishers exact test were performed.

was observed mainly in well-differentiated oral squamous cell carcinomas that showed better prognosis [37]. Thus, it appears that the role of Fra-1 as a tumor suppressor or oncogene may vary from tumor to tumor and on hostvirus interactions.

Considering oncogenic role of HPVs [38] and their cooperative interaction with AP-1 signaling [10,13], infection with HPV has been implicated as a possible etiological factor in the development of squamous cell carcinoma of the esophagus. Our results demonstrated unlike cervical cancers where HR-HPV infection is an essential etiological factor, the percentage of cases with HPV infection in ESCC was small and accounted for about one fifth of total cases. Occurrence of HPV infection in esophageal cancer is variable and conflicting, ranging from complete absence to detection of up to 60 to $70 \%$ mainly of high risk HPV types 16 and $18[8,39]$. Our earlier study on different subset of samples from the same region showed similar frequency of HPV16 infection [9]. Though consid-

Table 4: AP-I protein expression profile and their densitometric analysis in HPV negative and HPV positive cases of ESCC.

\begin{tabular}{|c|c|c|c|c|c|c|c|c|c|}
\hline \multirow[t]{2}{*}{ AP-I Family Member Protein } & \multicolumn{4}{|c|}{$\begin{array}{c}\text { HPV negative Cases } \\
(n=61)\end{array}$} & \multicolumn{4}{|c|}{$\begin{array}{l}\text { HPV positive Cases } \\
(n=14)\end{array}$} & \multirow[t]{2}{*}{ p value } \\
\hline & Nil & Weak & Medium & Strong & Nil & Weak & Medium & Strong & \\
\hline cJun & - & 5 & 20 & 36 & - & - & 4 & 10 & 0.6 \\
\hline JunB & 2 & 8 & 26 & 25 & - & 1 & 4 & 9 & 0.64 \\
\hline JunD & - & 7 & 19 & 35 & - & - & 2 & 12 & 0.41 \\
\hline cFos & - & - & 13 & 48 & - & - & - & 14 & ND \\
\hline FosB & 2 & 13 & 23 & 23 & - & 1 & 6 & 7 & 0.2 \\
\hline Fra-I & - & 14 & 10 & 37 & 11 & 3 & - & - & 0.001 \\
\hline Fra-2 & 8 & 10 & 15 & 28 & 3 & 6 & 3 & 2 & 0.03 \\
\hline
\end{tabular}

Arbitrary level of expression in Immunoblotting: strong $=>50 \%$; medium $=10-50 \%$; Weak $=1-10 \%$; and Nil/undetectable $=<1 \%$. Statistical calculation was done by grouping nil \& weak, medium \& strong together. Yates corrected chi-square/Fishers exact test were performed. 


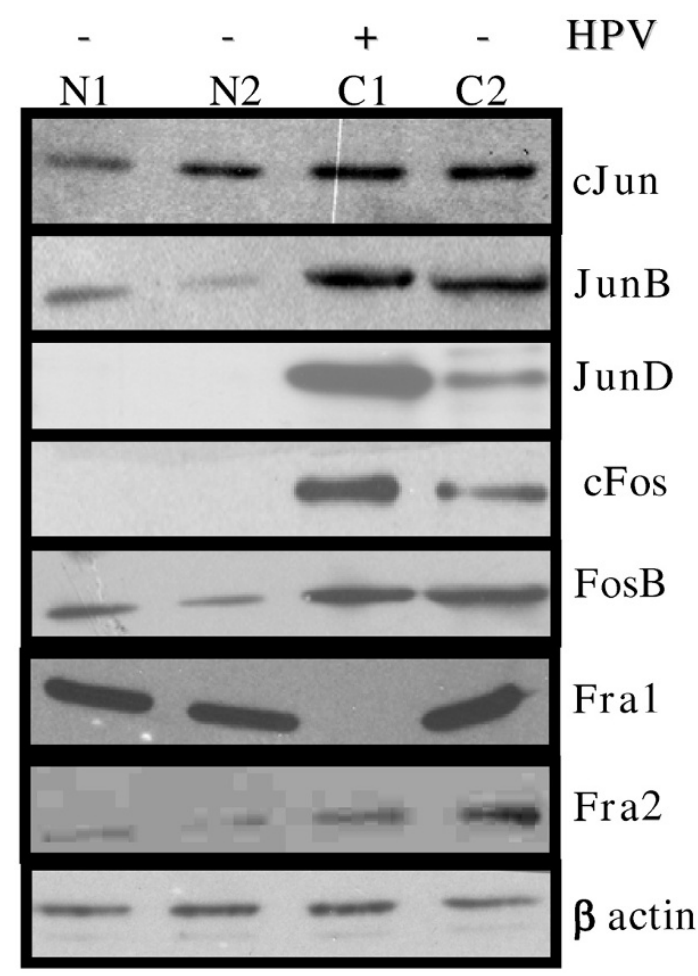

Figure 5

Western blots showing expression pattern of AP-I family of proteins in HPV positive and HPV negative esophageal cancer. Protein extracts from HPV positive $(\mathrm{Cl})$ and HPV negative (C2) tumor biopsies as well as their corresponding adjacent tissue $(\mathrm{NI}, \mathrm{N} 2)$ were separated in $10 \%$ SDS-PAGE and detected by all specific antibodies of API family proteins as indicated. All the blots were stripped and reprobed for $\beta$-actin levels to confirm equal loading and the quantitation of bands was performed densitometrically as indicated in methods.

erable proportions of esophageal cancers have been shown to have HPV infection and that too of high risk types, the etiological role of HPV in these cancers is not established. It is suggested that HPV infection when present may act as a co-factor or have synergistic effects with environmental carcinogens in the genesis of ESCC and/or their progression. We also demonstrate a significant correlation of HPV infection with smoking habit and intake of nitrosated compounds in salted tea [Table 2]. The entry of HPV in esophageal cancers appears to be in later stages as the infection was more prevalent in clinically advanced tumors. Therefore, HPV may significantly influence the disease progression rather than initiation. In contrast to genital cancers, it has been shown that HPV infection may be associated with better prognosis [14] as it is found more in well-differentiated squamous cell carcinomas of the head and neck [40] and may positively influence the treatment outcome [41]. Therefore, determi- nation of HPV status in esophageal cancer may also be helpful in predicting the treatment outcome.

\section{Conclusion}

Present investigation provides evidence of a constitutively activated AP-1 in esophageal cancers and demonstrates involvement of JunB, JunD and cFos as major DNA binding partners whereas it clearly negates the role of canonical AP-1 partner, cJun. Expression of AP-1 proteins and their DNA-binding activity was found to differ between HPV positive and HPV negative tumors. Considering that HR-HPV infection causes better prognosis in head and neck cancers, present findings may provide clue(s) for better understanding of HPV-mediated esophageal carcinogenesis and development of treatment strategies.

\section{Competing interests}

The authors declare that they have no competing interests.

\section{Authors' contributions}

SH carried out all experiments and primary manuscript writing. ACB contributed in designing and interpretation of the study. IS collected samples and performed DNA extraction. MAB Gastroenterologist who collected data from patients and performed surgery. MMM senior scientist who contributed to critical revision of the manuscript. SH conceived and participated in the study. MAS conceived, design and acquisition of data. SFB senior scientist who oversaw the work and critical revision of the manuscript. BCD senior Professor, who oversaw and guaranteed the work and for conception, design and critical corrections of the manuscript. All authors read and approved the final manuscript.

\section{Acknowledgements}

The work was supported by institutional grants from Indian Council of Medical Research (ICMR), New Delhi. Fellowship support to SH by ICMR.

\section{References}

I. Parkin DM, Bray F, Ferlay J, Pisani P: Global cancer statistics, 2002. CA Cancer J Clin 2005, 55:74- 108.

2. Siddiqi M, Preussmann R: Esophageal cancer in Kashmir--an assessment. / Cancer Res Clin Oncol 1989, I I 5: I I I-I I 7.

3. Kumar R, Mende P, Wacker CD, Spiegelhalder B, Preussmann R, Siddiqi M: Caffeine-derived N-nitroso compounds--I: Nitrosatable precursors from caffeine and their potential relevance in the etiology of oesophageal and gastric cancers in Kashmir, India. Carcinogenesis 1992, I3:2179-2।82.

4. Khuroo MS, Zargar SA, Mahajan R, Banday MA: High incidence of oesophageal and gastric cancer in Kashmir in a population with special personal and dietary habits. Gut 1992, 33: I I- I5.

5. Murtaza I, Mushtaq D, Margoob MA, Dutt A, Wani NA, Ahmad I, Bhat $M L:$ A study on $p 53$ gene alterations in esophageal squamous cell carcinoma and their correlation to common dietary risk factors among population of the Kashmir valley. World J Gastroenterol 2006, I 2:4033-4037.

6. Lam KY, Tsao SW, Zhang D, Law S, He D, Ma L, Wong J: Prevalence and predictive value of $\mathrm{p} 53$ mutation in patients with oesophageal squamous cell carcinomas: a prospective clinico-pathological study and survival analysis of 70 patients. Int J Cancer 1997, 74:212-219. 
7. Parkin DM, Bray F: Chapter 2: The burden of HPV-related cancers. Vaccine 2006, 24(Suppl 3): I I-25.

8. Syrjanen KJ: HPV infections and oesophageal cancer. J Clin Pathol 2002, 55:72I-728.

9. Katiyar S, Hedau S, Jain N, Kar P, Khuroo MS, Mohanta J, Kumar S, Gopalkrishna V, Kumar N, Das BC: p53 gene mutation and human papillomavirus (HPV) infection in esophageal carcinoma from three different endemic geographic regions of India. Cancer Lett 2005, 21 8:69-79.

10. Offord EA, Beard P: A member of the activator protein I family found in keratinocytes but not in fibroblasts required for transcription from a human papillomavirus type 18 promoter. J Virol 1990, 64:4792-4798.

II. Karamouzis MV, Konstantinopoulos PA, Papavassiliou AG: The activator protein-I transcription factor in respiratory epithelium carcinogenesis. Mol Cancer Res 2007, 5:109-120.

12. Thierry F, Spyrou G, Yaniv M, Howley P: Two API sites binding JunB are essential for human papillomavirus type 18 transcription in keratinocytes. J Virol 1992, 66:3740-3748.

13. de Wilde J, De-Castro Arce J, Snijders PJ, Meijer CJ, RosI F, Steenbergen RD: Alterations in AP-I and AP-I regulatory genes during HPV-induced carcinogenesis. Cell Oncol 2008, 30:77-87.

14. Mishra A, Bharti AC, Varghese P, Saluja D, Das BC: Differential expression and activation of NF-kappaB family proteins during oral carcinogenesis: Role of high risk human papillomavirus infection. Int / Cancer 2006, I I 9:2840-2850.

15. Coia LR, Myerson RJ, Tepper JE: Late effects of radiation therapy on the gastrointestinal tract. Int J Radiat Oncol Biol Phys 1995, 31:1213-1236.

16. Esophagus. In Manual for the Staging of Cancer 4th edition. Cancer AJCo. Philadelphia: JB Lippincott; 1992:57-59.

17. Das BC, Sharma JK, Gopalakrishna V, Luthra UK: Analysis by polymerase chain reaction of the physical state of human papillomavirus type 16 DNA in cervical preneoplastic and neoplastic lesions. J Gen Virol 1992, 73(Pt 9):2327-2336.

18. Kailash U, Soundararajan CC, Lakshmy R, Arora R, Vivekanandhan S, Das BC: Telomerase activity as an adjunct to high-risk human papillomavirus types 16 and 18 and cytology screening in cervical cancer. $\mathrm{Br} J$ Cancer 2006, 95:1250- I257.

19. Dignam JD: Preparation of extracts from higher eukaryotes. Methods Enzymol 1990, I 82: 194-203.

20. Rosl F, Das BC, Lengert M, Geletneky K, zur Hausen H: Antioxidant-induced changes of the AP-I transcription complex are paralleled by a selective suppression of human papillomavirus transcription. J Virol 1997, 71:362-370.

21. Prusty BK, Das BC: Constitutive activation of transcription factor AP-I in cervical cancer and suppression of human papillomavirus (HPV) transcription and AP-I activity in HeLa cells by curcumin. Int J Cancer 2005, I I 3:95 I-960.

22. Chang L, Karin M: Mammalian MAP kinase signalling cascades. Nature 200I, 4I 0:37-40.

23. Ransone LJ, Verma IM: Nuclear proto-oncogenes fos and jun. Annu Rev Cell Biol 1990, 6:539-557.

24. Angel $P$, Karin M: The role of Jun, Fos and the AP-I complex in cell-proliferation and transformation. Biochim Biophys Acto 1991, 1072:129-157.

25. Karin M, Liu Z, Zandi E: AP-I function and regulation. Curr Opin Cell Biol 1997, 9:240-246.

26. Shaulian E, Karin M: AP-I as a regulator of cell life and death. Nat Cell Biol 2002, 4:EI3I-I36.

27. Abdel-Latif MM, Windle H, Terres A, Eidhin DN, Kelleher D, Reynolds JV: Helicobacter pylori extract induces nuclear factorkappa B, activator protein-I, and cyclooxygenase-2 in esophageal epithelial cells. J Gastrointest Surg 2006, 10:55 I-562.

28. Dhar GM, Shah GN, Naheed B, Hafiza : Epidemiological trend in the distribution of cancer in Kashmir Valley. J Epidemiol Community Health 1993, 47:290-292

29. Passegue E, Jochum W, Behrens A, Ricci R, Wagner EF: JunB can substitute for Jun in mouse development and cell proliferation. Nat Genet 2002, 30:158-166.

30. Li T, Dai W, Lu L: Ultraviolet-induced junD activation and apoptosis in myeloblastic leukemia ML-I cells. J Biol Chem 2002, 277:32668-32676.

31. Robinson CM, Prime SS, Huntley S, Stone AM, Davies M, Eveson JW, Paterson IC: Overexpression of JunB in undifferentiated malignant rat oral keratinocytes enhances the malignant phenotype in vitro without altering cellular differentiation. Int J Cancer 200I, $91: 625-630$.

32. Wu MY, Zhuang CX, Yang HX, Liang YR: Expression of Egr-I, cfos and cyclin DI in esophageal cancer and its precursors: An immunohistochemical and in situ hybridization study. World | Gastroenterol 2004, 10:476-480.

33. Hu YC, Lam KY, Law S, Wong J, Srivastava G: Identification of differentially expressed genes in esophageal squamous cell carcinoma (ESCC) by cDNA expression array: overexpression of Fra-I, Neogenin, Id-I, and CDC25B genes in ESCC. Clin Cancer Res 2001, 7:2213-2221.

34. Soto U, Das BC, Lengert M, Finzer P, zur Hausen H, Rosl F: Conversion of HPV 18 positive non-tumorigenic HeLa-fibroblast hybrids to invasive growth involves loss of TNF-alpha mediated repression of viral transcription and modification of the AP-I transcription complex. Oncogene 1999, 18:3 I87-3198.

35. Sinke RJ, Tanigami A, Nakamura $Y$, Geurts van Kessel A: Reverse mapping of the gene encoding the human fos-related antigen-I (fra-I) within chromosome band I Iq I3. Genomics 1993, 18:165.

36. Shirsat NV, Shaikh SA: Overexpression of the immediate early gene fra-I inhibits proliferation, induces apoptosis, and reduces tumourigenicity of c6 glioma cells. Exp Cell Res 2003 , 29I:91-100.

37. Mishra A, Bharti AC, Saluja D, Das BC: Trans-activation and expression patterns of jun and fos/AP-I super-family proteins in human oral cancer. Int J Cancer 2009. DOI-10.1002/ ijc. 24807

38. Das BC, Hussain S, Nasare V, Bharadwaj M: Prospects and prejudices of human papillomavirus vaccines in India. Vaccine 2008 , 26:2669-2679.

39. de Villiers EM, Lavergne D, Chang F, Syrjanen K, Tosi P, Cintorino M, Santopietro R, Syrjanen S: An interlaboratory study to determine the presence of human papillomavirus DNA in esophageal carcinoma from China. Int J Cancer 1999, 81:225-228.

40. Fakhry C, Gillison ML: Clinical implications of human papillomavirus in head and neck cancers. I Clin Oncol 2006, 24:2606-26II.

41. Datta NR, Kumar P, Singh S, Gupta D, Srivastava A, Dhole TN: Does pretreatment human papillomavirus (HPV) titers predict radiation response and survival outcomes in cancer cervix?-a pilot study. Gynecol Oncol 2006, 103:100-105.

\section{Pre-publication history}

The pre-publication history for this paper can be accessed here:

\section{http://www.biomedcentral.com/1471-2407/9/329/pre}

pub

Publish with Bio Med Central and every scientist can read your work free of charge

"BioMed Central will be the most significant development for disseminating the results of biomedical research in our lifetime. "

Sir Paul Nurse, Cancer Research UK

Your research papers will be:

- available free of charge to the entire biomedical community

- peer reviewed and published immediately upon acceptance

- cited in PubMed and archived on PubMed Central

- yours - you keep the copyright 